\title{
Retrospective Analysis of Therapy for Locally Advanced Oral Cancer : Radiotherapy Alone and Thermoradiotherapy
}

\author{
ORAZAKHMET K. KURPESHEV ${ }^{1}$, VALENTINA V. OSTAPENKO ${ }^{2 *}$, \\ YURI S. MARDYNSKY ${ }^{3}$, NIKOLAI A. CHUSHKIN ${ }^{4}$
}

\begin{abstract}
${ }^{1}$ Divisions of Local and Whole-Body Hyperthermia and 3Radiotherapy, Medical Radiological Research Center of the Russian Academy of Medical Sciences, 4, Korolyeva, Obninsk 249036, Russia

${ }^{2}$ Division of Hyperthermia, Bio-Thera Clinic, 14-4, Yochomachi, Shinjuku-ku, Tokyo 162-0055, Japan

${ }^{4}$ Division of Radiotherapy, Far-East State Medical University, 38, Muravyova-Amurskogo, Khabarovsk 68000, Russia
\end{abstract}

Abstract : Patients with locally advanced oral squamous cell carcinomas (T3-4N0-3M0) treated with RT or HT combined with RT (HRT) were analyzed retrospectively. The RT group consisted of 31 patients (M/F-27/4), and the HRT group consisted of 32 patients (M/F-29/3). RT was performed using conventional fractionation (2 Gy delivered 5 times/week) for a total dose of 54-60 Gy with a 2 week split course after delivery of 36-40 Gy. Regional HT was performed using a Supertherm EP40 (40.68 MHz) capacitive heating device (Moscow, Russia), for 60-70 min 3 times a week for a total of 8-10 times. Average tumor temperatures were $42.7 \pm 0.2^{\circ} \mathrm{C}$. RT was performed within $10-15$ min after the end of HT. Complete response (CR) of primary tumors was achieved in 20 patients $(62.5 \%)$ treated with HRT, and in 11 patients treated with RT alone $(35.5 \%)(p<0.05)$. There was a median time to recurrence of 36 months in the HRT group compared to 9 months in the RT group $(p<0.01)$. At the same time, the use of HT was associated with an increased incidence of radiation-induced mucositis. Median survival time for overall survival was better for the HRT group (48.0 months vs. 26 months for the RT group) $(p<0.05)$. In addition, employment of HT did not influence the frequency of distant metastases. From this aspect, disease-free survival was not statistically different between the two therapeutic approaches. This study demonstrates that regional HT confers a significant local control and long-term survival benefit with an acceptable toxicity risk in patients with advanced oral cancer who are receiving RT.

Key Words : oral cancer, radiotherapy, regional hyperthermia, response, survival

\section{Introduction}

Oral cancer is the sixth most common cancer in the world, with an annual estimated incidence of around $275,000^{1)}$. More than $65 \%$ of the patients start treatment at advanced stages, and therefore there

Received 10 July, 2009, Accepted 1 September, 2009. *Corresponding author: Tel, +81-3-5919-1762; Fax, +81-3-5919-1702 ; e-mail,valentina@bio-c.jp

doi : $10.3191 /$ thermalmed.25.59

(C) 2009 Japanese Society for Thermal Medicine 
is a mortality rate of up to $25-40 \%$ during the first year after diagnosis ${ }^{2-4)}$. This malignancy has been reported to be responsible for 2 to 3 percent of all cancer deaths in the USA ${ }^{5)}$.

Anatomic and functional characteristics of the head and neck area are such that these tumors have a tendency towards early invasive growth, and a tendency to lead to metastases in the neck lymph nodes. These conditions therefore lead to limited treatment options ${ }^{6-8)}$. The choice of treatment modality depends on the stage and anatomic site. Early stage tumors are treated with a single modality therapy: surgery alone or radiation alone. In particular, radiotherapy (RT) used as single treatment modality has been used for more than $80 \%$ of the patients with oral cancer. However, RT alone is not sufficient to produce satisfactory treatment outcomes, and therefore treatment of the majority of locally advanced head and neck tumors typically requires a multidisciplinary approach, including radiotherapy and chemotherapy ${ }^{9-11)}$. Overall 5-year survival rates for patients treated with either of the conventional methods vary from $6 \%$ to $50 \%$, depending on the tumor stage and tumor site ${ }^{12-14)}$. Regional metastases dramatically influence survival rates ${ }^{7,15,16)}$.

The aim of the work presented here was to determine if the use of regional hyperthermia (HT) with RT was beneficial in terms of better local and regional control, and consequently for long-term survival.

\section{Patients and Treatments \\ Patients}

Sixty three patients (M/F ratio: 56/7) with locally advanced oral cancer (T3-4N0-3M0) who were treated in the Medical Radiological Research Center of the Russian Academy of Medical Sciences, Obninsk, and in the Far-East State Medical University, Khabarovsk, in the period from 1998 to 2003 were retrospectively analyzed. Patients were randomized to receive either RT or HRT. Patients with systolic blood pressure over $160 \mathrm{mmHg}$ or less than $100 \mathrm{mmHg}$, who had a stroke, a hypertensive crisis, or had a risk of bleeding were excluded from this study. The clinical characteristics of the patients are summarized in Table I. For staging, the TNM classification of the UICC (1989) was used ${ }^{17)}$.

\section{Radiotherapy}

Patients were irradiated using gamma ray ${ }^{60} \mathrm{Co}$ sources with standard fields encompassing the gross disease. Treatment fields were individualized for each patient. In both groups, RT was performed using conventional fractionation with single doses of 2 Gy delivered 5 times a week for a total dose of 54-60 Gy, and with a 2 week split course after delivery of 36-40 Gy.

\section{Hyperthermia}

Regional HT was performed using a Supertherm EP40 (40.68 MHz) capacitive heating device (Space Technology Center, Moscow, Russia) with patients in a sitting position as shown in Fig. 1. A pair of electrodes $8 \times 11 \mathrm{~cm}$ or $11 \times 15 \mathrm{~cm}$ were used, and were positioned to cover both the primary tumors and regional lymph nodes. HT was usually delivered starting from the $6^{\text {th }} \mathrm{RT}$ fraction, and was delivered 3 times a week for a total of 8-10 sessions. Treatment during the first session was for 40-50 min, and then for 60-70 min for the remaining sessions. The time required to reach the target temperature was 6 to 10 min, and the tumor temperature was maintained at 41.4 to $41.7^{\circ} \mathrm{C}$ at the periphery, and $42.4-43.2^{\circ} \mathrm{C}$ at the center. RT was started within 10-15 min after delivery of HT. Temperature measurements were performed with the use of fiber-optic invasive thermosensors. Sensors were placed in the tumor and 
Table I. Patient clinical characteristics

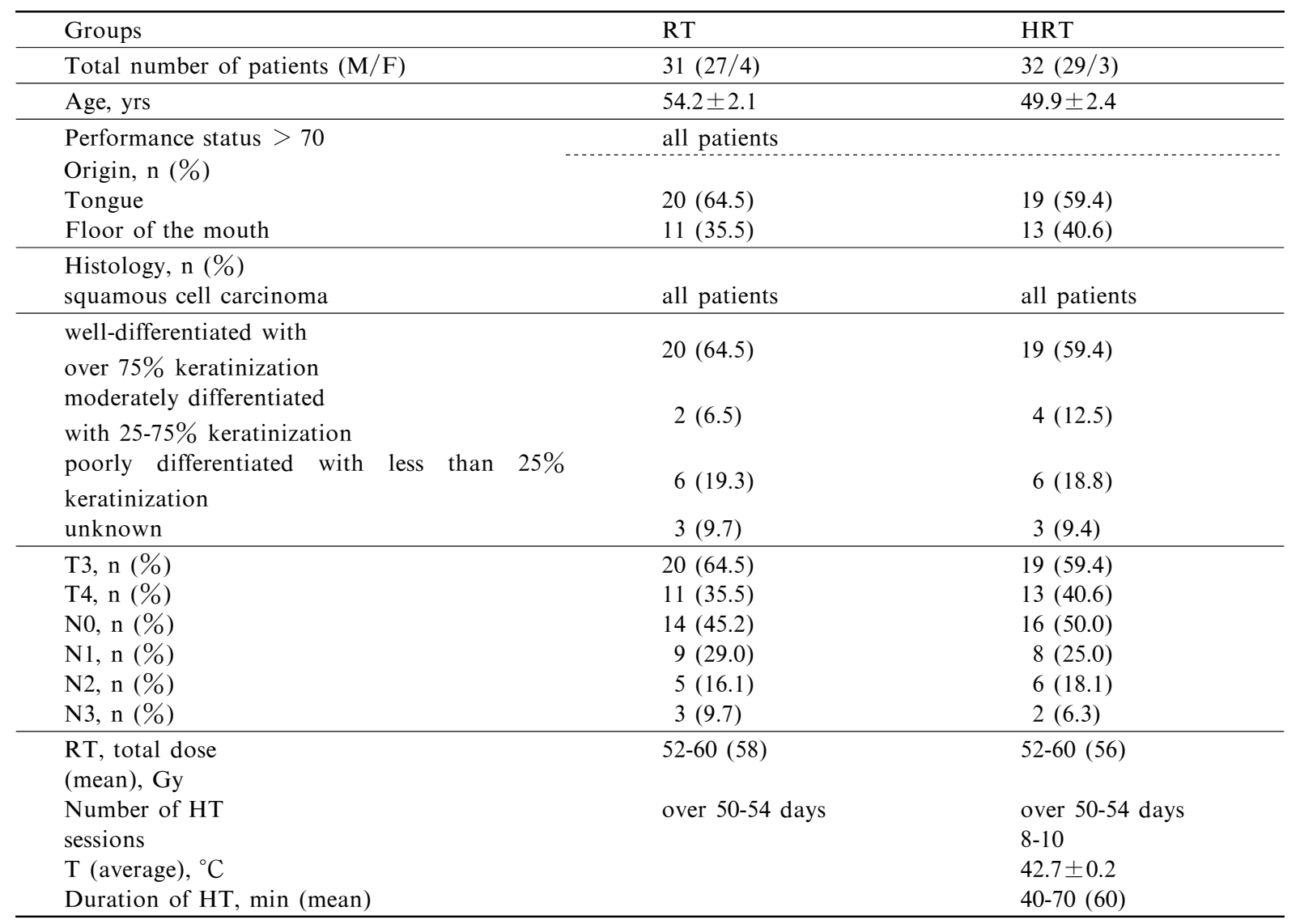

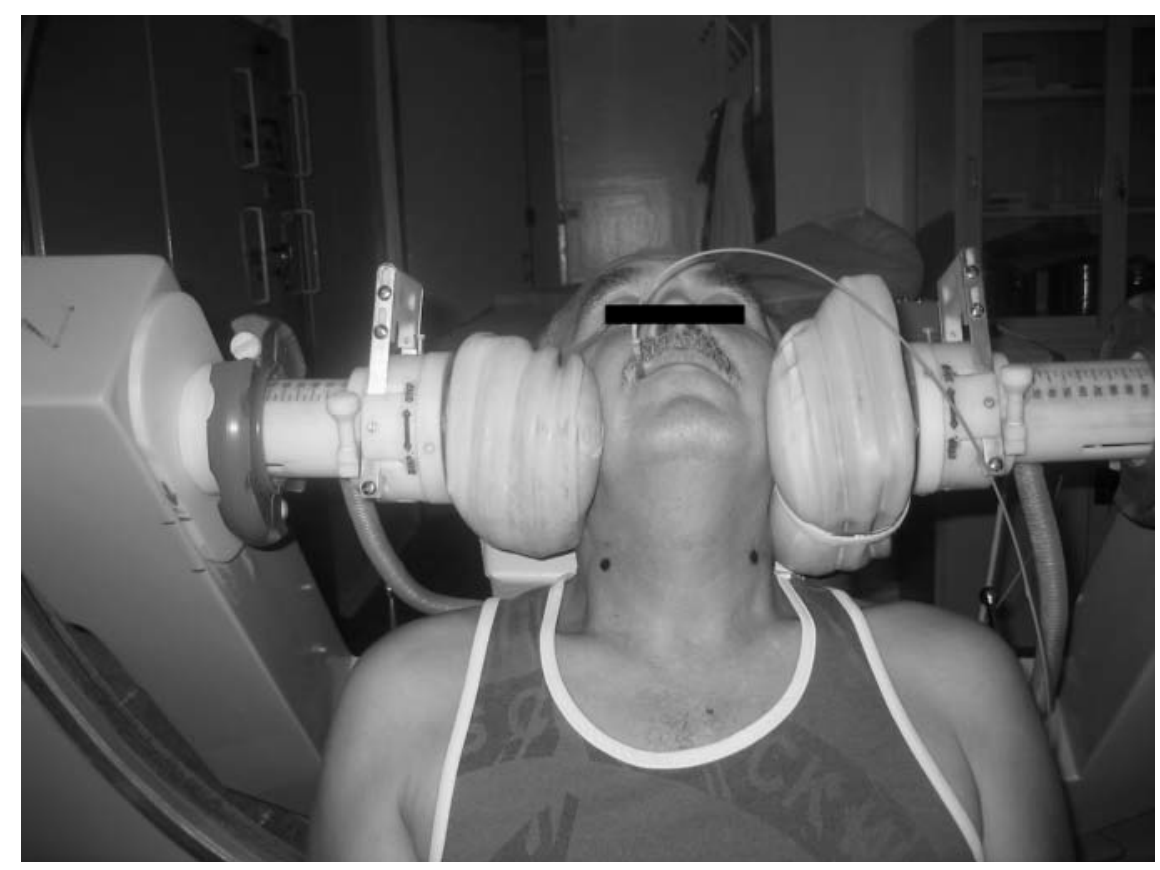

Fig. 1. HT using the Supertherm EP-40 on a patient with tongue cancer (T4N3M0). 
positioned to be parallel to the surface of the electrodes. During treatment, the patient's skin was cooled with a circulating water system. It was important to remove tooth crowns and bridges in patients prior to HT because any metal items could change the orientation of the electric field lines and cause burns in the surrounding soft tissues. To reduce salivation, $1 \mathrm{ml}$ of $0.1 \%$ of atropine was injected subcutaneously before placement of the thermosensor. To secure the sensors and to reduce pain, sensors were pressed tightly to the tumors with gauze soaked in a $0.5 \%$ Novocain solution.

\section{Statistical analysis}

The primary end point in this analysis was the local response rate evaluated at 4-5 weeks after the end of therapy. Duration of local control was defined as the time from the first treatment to a local recurrence.

Secondary end points included the overall survival rate, local and regional recurrence free survival, distant metastasis free survival rates, and acute and late toxic responses associated with therapy. Fisher's exact test was used to compare the binary outcome data for the two groups. Overall survival was determined by counting from the day of the randomization up to the day the patient died (regardless of the cause of death), or to the date of the patient's last visit. Recurrence-free survival was calculated from the day of the randomization to the recurrence date, or the date of the patient's last visit. Analysis of recurrence-free survival was performed in patients with complete regression of regional metastases and in patients without evidence of metastases before treatment.

Duration of disease-free survival was calculated with the day of the randomization defined as day zero, up to the date of any of clinical event, such as tumor regrowth, recurrence of the primary tumor, metastases to regional lymph nodes, distant metastases or death. Time was counted up to the patient's last examination in the clinic. Log-rank tests were used to compare the two groups by observing time-to-event points: the time to local failure, and the time of overall survival. Kaplan-Meyers time-to-event curves are presented. All reported $\mathrm{p}$ values are two-sided, and $p \leq 0.05$ was considered as statistically significant. The severity of oral mucositis was graded with the help of the Radiation Therapy Oncology Group (RTOG) scale where grade 1 referred to erythema of the mucosa, grade 2 to a patchy reaction $<1.5 \mathrm{~cm}$, grade 3 to a confluent reaction $>1.5 \mathrm{~cm}$, and grade 4 to a necrosis or deep ulceration with or without bleeding. This scale is an integral part of the NCI-CTC version 2.0 ${ }^{18)}$. For assessment of late complications, the Subjective, Objective, Management, Analytic (SOMA) scale was employed, where grade 1 refers to island atrophy or telangiectasia; grade 2 to diffuse atrophy, telangiectasia, or superficial ulcers; grade 3 to deep ulcers not involving cartilage or bone; and grade 4 to a deep ulcers involving bone or cartilage (osteomyelitis) ${ }^{19)}$. The Chi-square test was employed to evaluate differences in complication rates between the two groups. Calculations were performed with the help of Statistica, v. 6.0 (StatSoft, Inc.) software.

\section{Results}

\section{Treatment responses}

As shown in Table II, local control was significantly better in the HRT group, whereas regional responses did not differ significantly between the two groups (Table III). However, it is worth noticing that metastases in the submandible area, which were covered by the electrodes during HT, preferentially 
displayed a complete regression in the HRT group. Specifically, there was a total of 27 metastases in that area in 17 patients in the RT group, and a total of 25 metastases in 16 patients treated with HRT. CR was observed in 6 patients $(22.2 \%)$ in the RT group vs. 12 patients $(48.0 \%)$ in the HRT group $(p=0.05)$. For a comparison, with the neck metastases, (21 and 23 respectively), CR was seen in $23.8 \%$ of the RT group vs. $30.4 \%$, in the HRT group. Thus, there was not a significant difference between the groups with this endpoint.

\section{Survival}

As shown in Fig. 2, overall survival was not statistically different between the two groups, as evaluated with the Logrank test, whereas the median survival time was better in the HRT group (48.0 months vs. 26 months for the RT group) $(p<0.05)$. Local control was superior in the HRT group $(p<$

Table II. Primary tumor response rate

\begin{tabular}{|l|l|l|l|l|}
\hline \multirow{2}{*}{ Group } & \multirow{2}{*}{ Number of patients } & CR & PR & NC \\
\cline { 2 - 5 } & & N (\%) & N (\%) & N (\%) \\
\hline RT & 31 & $11(35.5)$ & $11(35.5)$ & $9(29.0)$ \\
\hline HRT & 32 & $20(62.5)^{*}$ & $10(31.3)$ & $2(6.2)$ \\
\hline
\end{tabular}

$\mathrm{CR}$, complete response; PR, partial response; NC, no change. $* p<0.05$

Table III. Regional lymph node response rate

\begin{tabular}{|l|l|l|l|l|}
\hline \multirow{2}{*}{ Group } & Number of patients with lymph node metastases & CR & PR & NC \\
\cline { 2 - 5 } & & N (\%) & N (\%) & N (\%) \\
\hline RT & 17 & $5(29.4)$ & $7(41.2)$ & $5(29.4)$ \\
\hline HRT & 16 & $8(50.0)^{*}$ & $5(31.3)$ & $3(18.7)$ \\
\hline
\end{tabular}

$\mathrm{CR}$, complete response; PR, partial response; NC, no change. $* p=0.2$

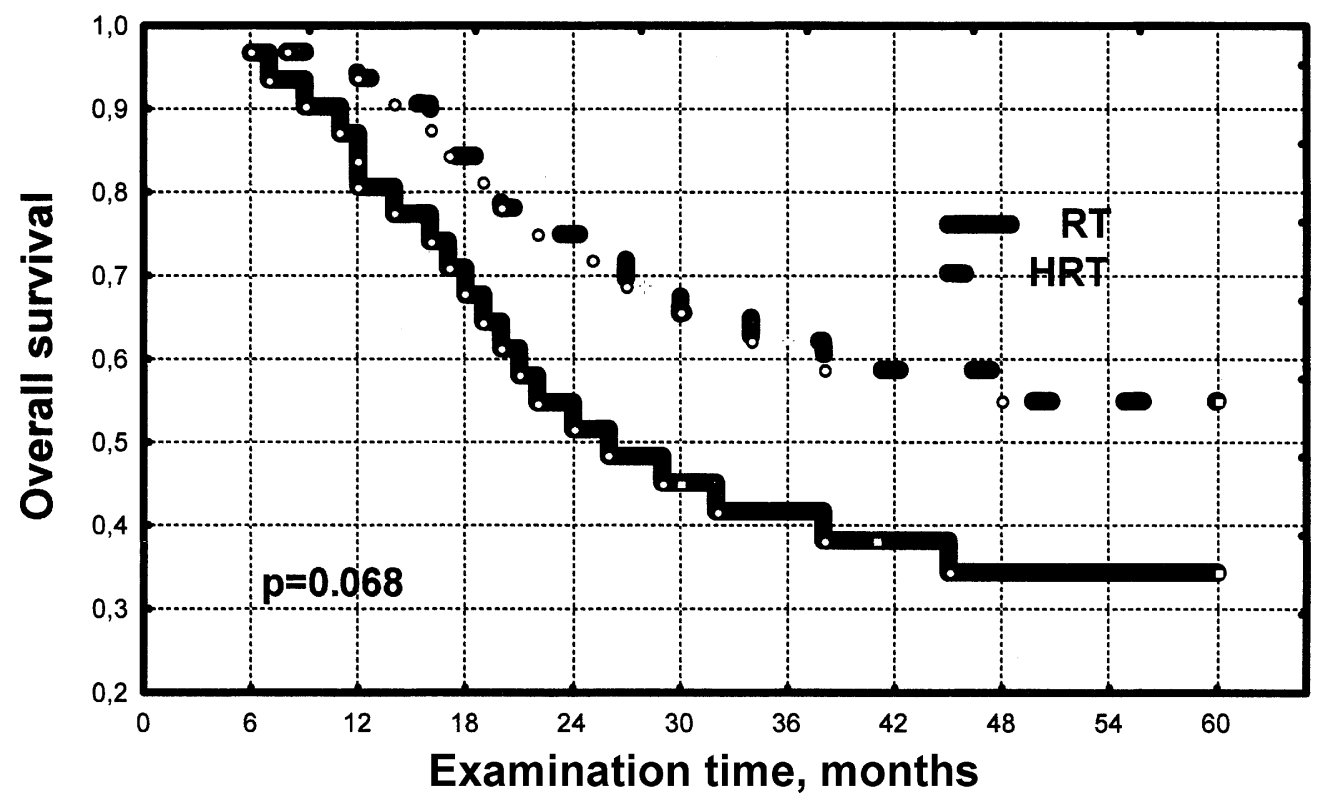

Fig. 2. Overall survival 
0.05), with a median time to recurrence of 36 months compared to 9 months for the RT group $(p<0.01)$. The effectiveness of the combined therapy approach was not significantly better than RT alone in terms of regional control (Fig. 4, $p=0.059$ ). In addition, as shown in Fig. 5, the use of HT did not influence

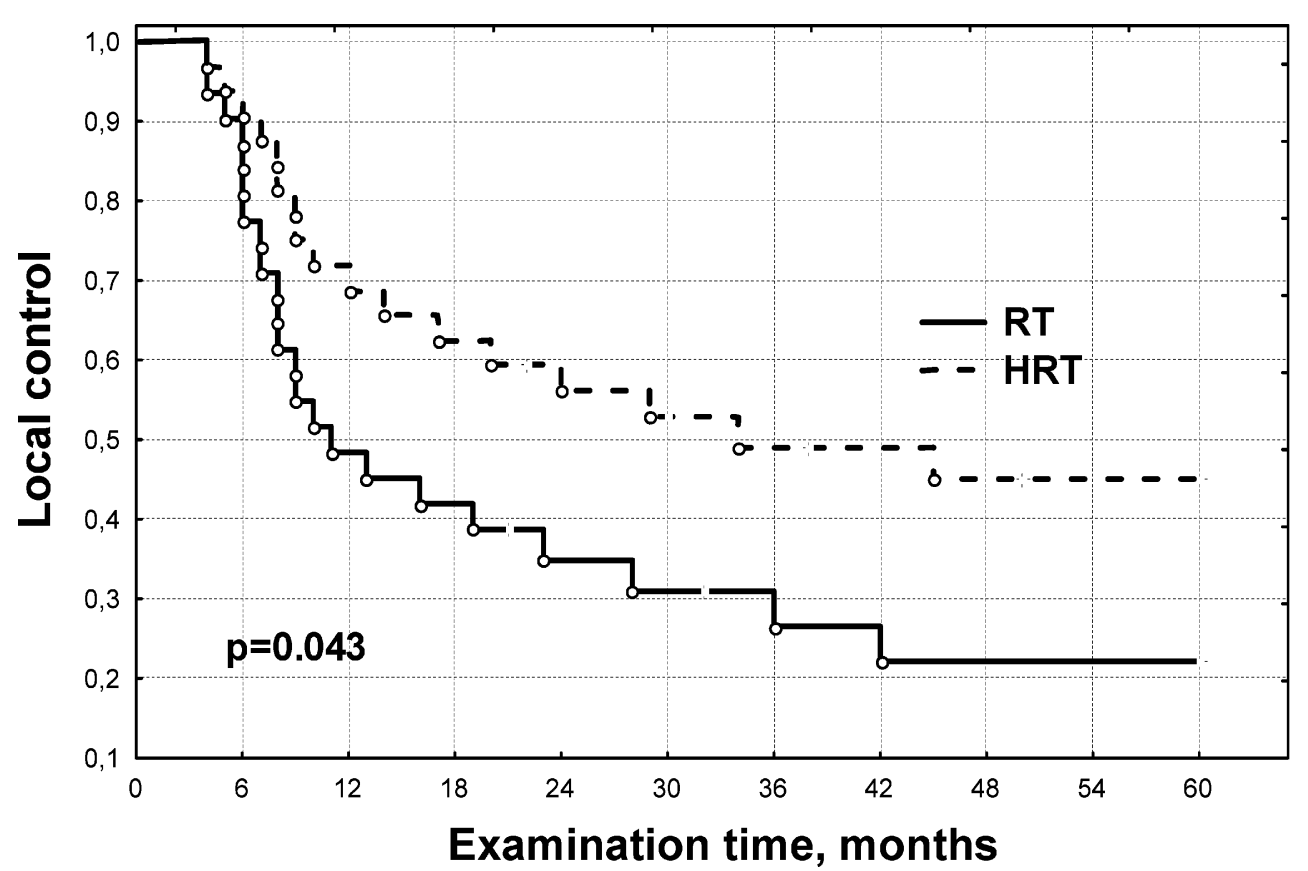

Fig. 3. Time to recurrence

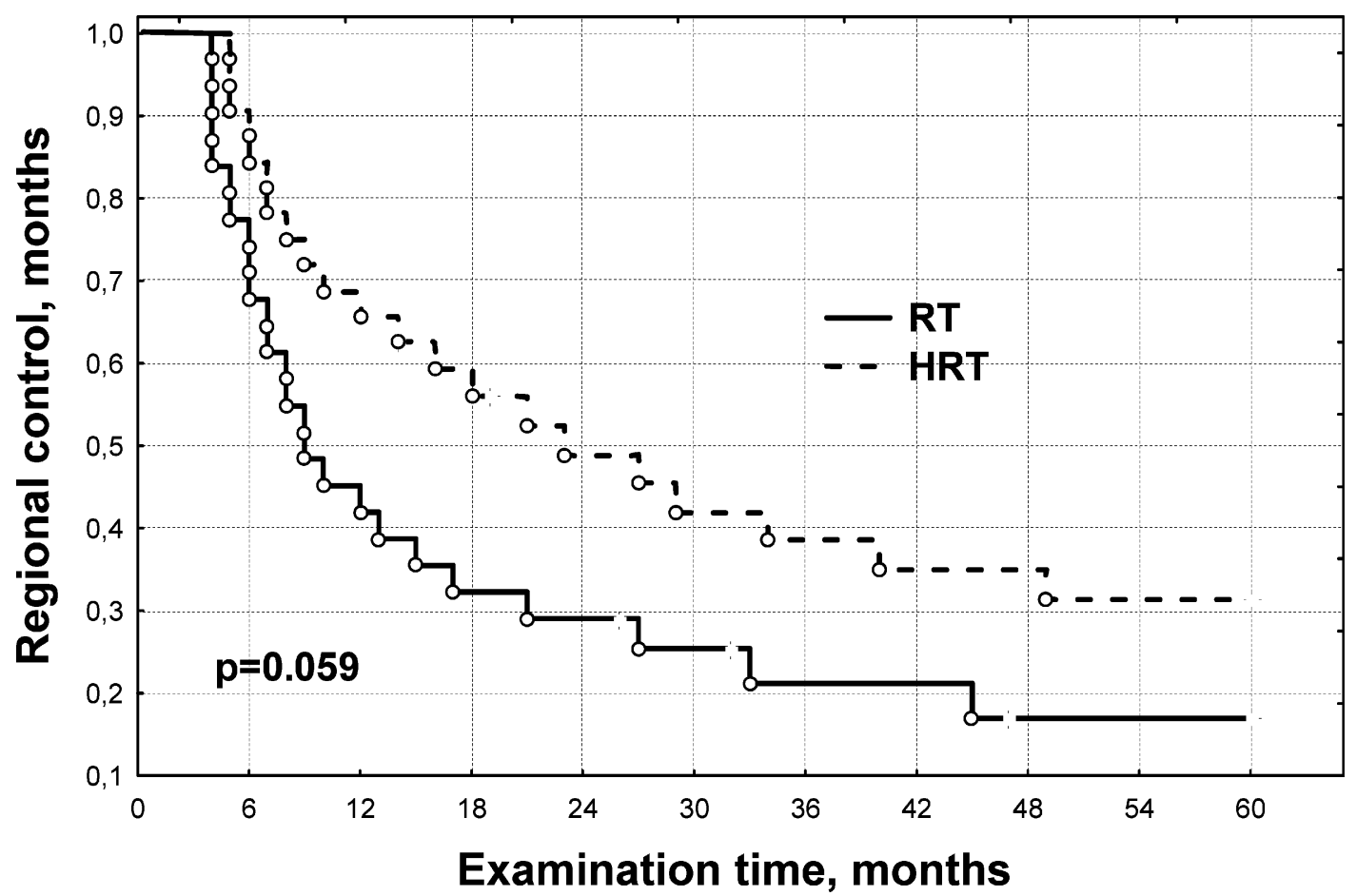

Fig. 4. Regional control 
the frequency of distant metastases. From this aspect, disease-free survival was not statistically different between the two therapeutic approaches (Fig. 6).

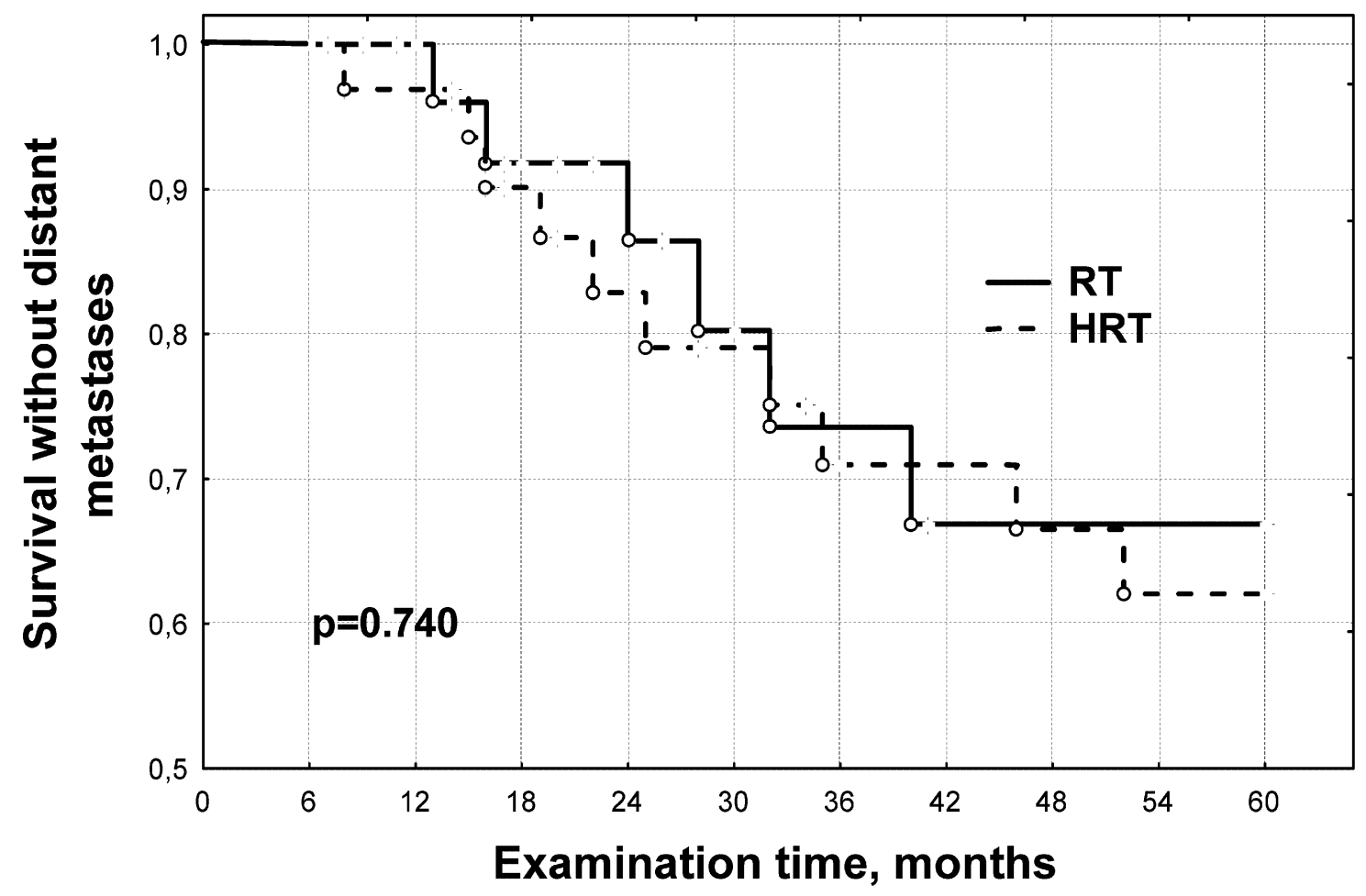

Fig. 5. Survival without distant metastases

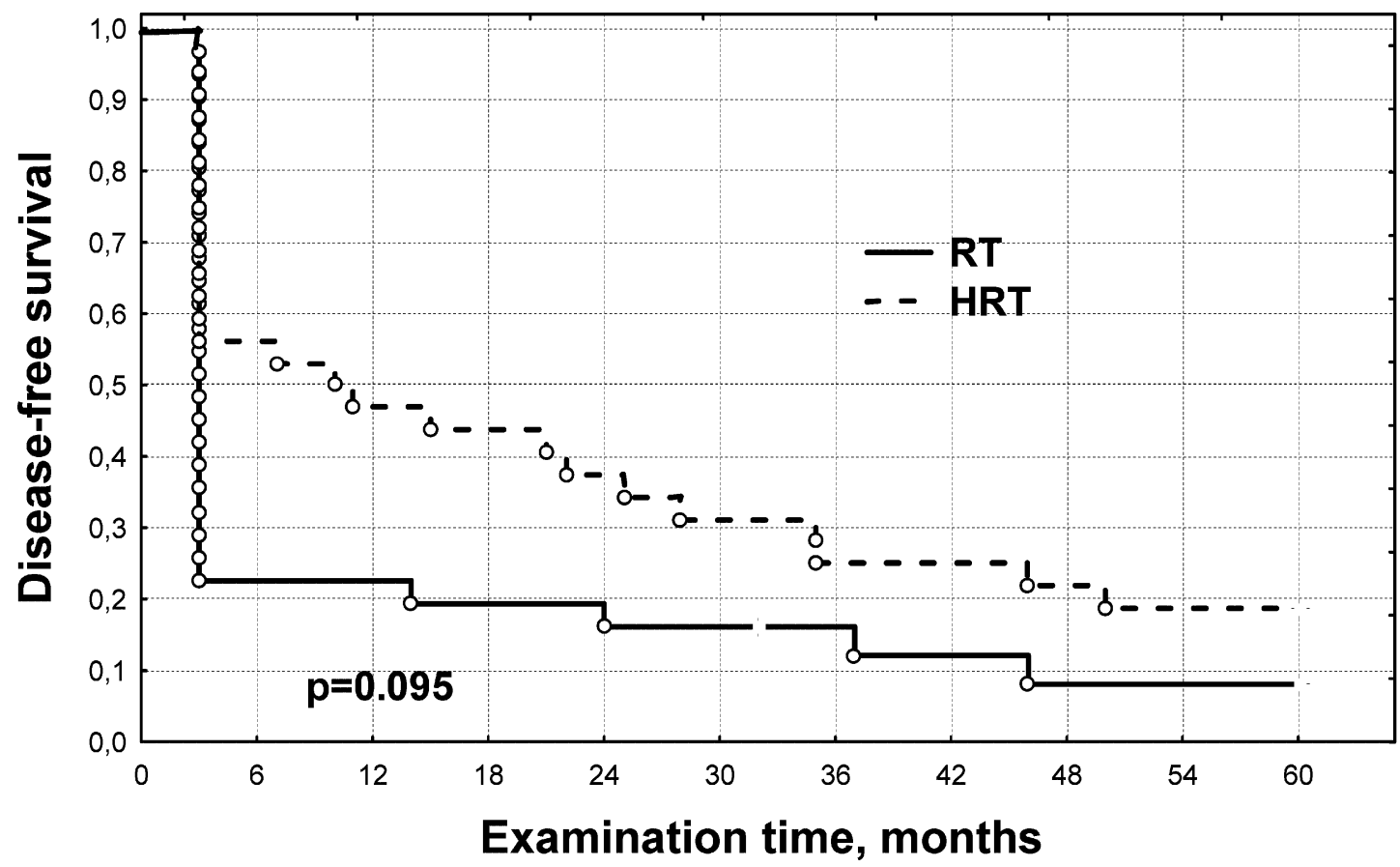

Fig. 6. Disease-free survival 


\section{Complications}

\section{Acute toxicity}

Acute radiation toxicity was observed in all patients to some extent. As shown in Table IV, the addition of HT was associated with more severe mucositis.

\section{Late toxicity}

In the RT group, there was a grade 3 ulcer in one patient, whereas in the HRT group this was noticed in 3 patients. In addition, one patient in the HRT group had osteomyelitis (grade 4). Differences in the rate of observation of late toxicity responses between the RT and HRT groups were not significant.

\section{Discussion}

Squamous cell carcinomas of the head and neck account for $5 \%$ of newly diagnosed cancers in adults in the United States, and for $8 \%$ of cancers worldwide ${ }^{3,20}$. The disease is potentially curable at an early stage, but most patients present with locally advanced disease. After standard therapy (surgery and radiation), only 30 to $50 \%$ of patients with locally advanced disease live for 3 years, and locoregional recurrences or distant metastases develop in 40 to $60 \%$ of these patients ${ }^{21-25)}$. Various strategies to improve outcomes by coordinating chemotherapy with surgery and radiotherapy have been tried, but the optimal schedule for integrating chemotherapy into the management of this disease has yet to be defined $^{26)}$. Conventional head and neck radiotherapy, a standard approach for locoregionally advanced disease, is associated with a variety of well-known acute and long-term toxic responses. Radiation mucositis with associated pain is experienced by virtually all patients, and can last for 3-8 weeks following treatment ${ }^{27)}$. Chronic radiation toxicity, including mucosal fibrosis and atrophy, xerostomia, dental decay, soft tissue necrosis, osteonecrosis and taste disturbances (dysgeusia, ageusia), can occur in many patients ${ }^{28)}$.

Unplanned RT breaks and prolongation of the RT time are associated with lower survival and locoregional control rates when radiotherapy or concurrent chemoradiotherapy is used in the curative treatment of head and neck cancer. As the intensity of treatment regimens has escalated in recent years, clinical outcomes generally have improved. However, more intensive therapy also increases the incidence of treatment-related toxic responses, particularly those impacting the mucosal lining. For instance, altered radiation fractionation regimens that incorporate acceleration and/or hypefractionation were shown to improve locoregional control but also increased acute toxic responses in these patients ${ }^{29-31)}$. For this category of patients a split radiation regimen was reported which was aimed at diminishing the severity of mucositis. At the same time, as reported, caution was exercised so as not to extend the split time to over 14 days, in order to prevent a possible decrease in patient response ${ }^{32)}$. Therefore, there it is still challenging to select the best treatment regimen, and that means that radiation oncologist is often put in a position where he/she has to find a compromise between a better response and a higher acute toxicity. 
In our practice, the majority of patients developed radiation-induced mucositis during $\mathrm{RT}$ for oral cancer, thus making it difficult to continue RT up to the planned total dose. As a result, unplanned treatment breaks were a common practice for this category of patients. Therefore, a protocol with planned treatment breaks was agreed on. At the same time efforts were made to make the duration of the split as short as possible (14 days), and that of the overall radiation treatment time up to 60 days, in an attempt to diminish the negative influence of a split on treatment responses.

Since radiation alone does not lead to a desirable response rate, combined approaches must be used. Efforts to improve the efficacy of treatments have led to the use of multimodality approaches with combinations of surgery, radiotherapy and chemotherapy. The addition of chemotherapy to radiotherapy following surgery for resectable head and neck cancer with high-risk features shows improved locoregional control and disease-free survival ${ }^{33)}$. Moreover, chemoradiotherapy has been recognized recently as a standard therapy for these malignancies. However, in both a definitive and post-operative head and neck setting, an enhanced survival outcome is accompanied by an increase in overall treatment toxicity profiles ${ }^{34-36)}$. Regional HT is considered to be another promising option to improve RT response in this category of patients. There are 7 positive randomized trials where RT combined with HT resulted in better outcomes than RT alone, and these reports included patients with head and neck tumors ${ }^{37-43)}$. In addition, there are other non-randomized trials, which have demonstrated promising results ${ }^{44,45)}$. Here, an attempt was made to employ HT delivered before RT to improve radiation responses. The rationale for this kind of combination is evidence from earlier clinical trials in which oxygen had been measured before and after tumor heating: increased tumor oxygenation was documented after heating ${ }^{46,47)}$. As a consequence of increased tumor oxygenation, it would be reasonable to expect more efficient manifestations of radiation effects.

It was demonstrated that the use of HT improved both the primary tumor and local lymph node response rates. At the same time, the use of HT resulted in additional early radiation damage to the oral mucosa, and there was a tendency to see an increased risk for late complications such as radiation ulceration and osteomyelitis associated with the use of HT in one patient. Concerning long term treatment outcomes, recurrence-free survival was superior with the combined regimen, and in addition, there was a tendency to achieve a better regional control rate. The lack of statistically significant improvement in regional control was probably caused by technical limitations, because not all of the lymph nodes were covered by the electrodes. It appears likely that further improvements in the heating techniques used for delivering regional HT, or additional HT sessions, might make it possible to further improve clinical outcomes in future trials. Metastases free survival was essentially the same between the two groups, showing that HT did not increase the risk of metastases for these patients. In this connection, disease-free survival was not statistically different between the two therapeutic approaches.

In conclusion, HT was shown to be an important tool in augmenting the effectiveness of radiotherapy in oral cancer patients with an acceptable added risk for acute toxicity.

\section{References}

1) Warnakulasuriya S. : Global epidemiology of oral and oropharyngeal cancer. Oral Oncology, 45 : $309-316,2009$.

2) Al-Sarraf M., Pajak T.F., Cooper J., Mohiuddin M., Herskovic A., Ager P.J. : Chemo-radiotherapy in patients with 
locally advanced nasopharyngeal carcinoma. A radiation therapy oncology group study. J Clin Oncol, 8 : 1342-1351, 1990.

3) Jemal A., Thomas A., Murray T., Thun M. : Cancer Statistics, 2002. CA Cancer J Clin, 52 : 23-47, 2002.

4) Psyrri A., Prezas L., Burtness B.: Oropharyngeal cancer. Clin Adv Hematol Oncol, 6 : 604-612, 2008.

5) Horowitz A.M., Drury T.F., Goodman H.S., Yellowitz J.A. : Oral pharyngeal cancer prevention and early detection. Dentists' opinions and practices. 2000. J Am Dent Assoc, 131: 453-462, 2000.

6) Barasch A., Safford M., Eisenberg E. : Oral cancer and oral effects of anticancer therapy. Mt Sinai J Med, 65 : 370-377, 1998.

7) Brunin F., Mosseri V., Jaulerry C., Point D., Cosset J.M., Rodriguez J. : Cancer of the base of the tongue : past and future. Head Neck, $21: 751-759,1999$.

8) Sanderson R.J., Ironside J.A. : Squamous cell carcinomas of the head and neck. BMJ, 325 : 822-827, 2002.

9) Chitapanarux I., Lorvidhaya V., Kamnerdsupaphon P., Sumitsawan Y., Tharavichitkul E., Sukthomya V., Ford J. : Chemoradiation comparing cisplatin versus carboplatin in locally advanced nasopharyngeal cancer: Randomized, non-inferiority, open trial. Eur J Cancer, 43 : 1399-1406, 2007.

10) Jones A.S., Beasley N., Houghton D., Husband D.J.: The effects of age on survival and other parameters in squamous cell carcinoma of the oral cavity, pharynx and larynx. Clin Otolaryngol, 23: 51-56, 1998.

11) Jones A.S., Husband D., Rowley H. : Radical radiotherapy for squamous cell carcinoma of the larynx, oropharinx and hypopharinx : patterns of reccurence, treatment and survival. Clin Otolaringol, 23: 496-511, 1998.

12) Fein D.A., Lee W.R., Amos W.R., Hinerman R.W., Parsons J.T., Mendenhall W.M., Stringer S.P., Cassisi N.J., Million R.R. : Oropharyngeal carcinoma treated with radiotherapy: a 30-year experience. Int J Radiat Oncol Biol Phys, 34 : 289-296, 1996.

13) Hoffman H.T., Karnell L.H., Funk G.F., Robinson R.A., Menck H.R.: The National Cancer Data Base report on cancer of the head and neck. Arch Otolaryngol Head Neck Surg, 124: 951-962, 1998.

14） Lee W.R., Mendenhall W.M., Parsons J.T., Million R.R., Cassisi N.J., Stringer S.P. : Carcinoma of the tonsillar region : a multivariate analysis of 243 patients treated with radical radiotherapy. Head Neck, 15 : 283-288, 1993.

15) Pinsolle J., Pinsolle V., Majoufre C., Duroux S., Demeaux H., Siberchicot F. : Prognostic value of histologic findings in neck dissections for squamous cell carcinoma. Arch Otolaringol Head Neck Surg, 123: 145-148, 1997.

16) Sherman A.C., Simonton S., Adams D.C., Latif U., Plante T.G., Burns S.K., Poling T. : Assessing quality of life in patients with head and neck cancer : cross-validation of the European Organization for Research and Treatment of Cancer (EORTC) Quality of Life Head and Neck module (QLQ-H\&N35). Arch Otolaryngol Head Neck Surg, 126 : 459-467, 2000.

17) Spiessl B., Beahrs O.H., Hermanek P., Hutter R.V.P., Scheibe O., Sobin L.H., Wagner G. : TNM atlas : illustrated guide to the TNM/pTNM-classification of malignant tumours. $3^{\text {rd }}$ ed. Berlin : Springer-Verlag, 1989.

18) National Cancer Institute Common Toxicity Criteria. Version 2.0, June 1, 1999. Available at : http://ctep.info.nih.gov.

19) Pavy J.J., Denekamp J., Letschert J., Littbrand B., Mornex F., Bernier J., Gonzales-Gonzales D., Horiot J.C., Bolla M., Bartelink H. : Late effects toxicity scoring: The SOMA scale. Int J Radiat Oncol Biol Phys, 31 : 1043-1047, 1995.

20) Jemal A., Siegel R., Ward E., Hao Y., Xu J., Murray T., Thun M.J. : Cancer statistics. CA Cancer J Clin 56 : 106-130, 2006.

21) Adelstein D.J., Li Y., Adams G.L., Wagner H.Jr., Kish J.A., Ensley J.F., Schuller D.E., Forastiere A.A. : An Intergroup phase III comparison of standard radiation therapy and two schedules of concurrent chemoradiotherapy in patients with unresectable squamous cell head and neck cancer. J Clin Oncol, 21 : 92-98, 2003.

22) Denis F., Garaud P., Bardet E., Alfonsi M., Sire C., Germain T., Bergerot P., Rhein B., Tortochaux J., Calais G. : Final results of the 94-01 French Head and Neck Oncology and Radiotherapy Group randomized trial comparing radiotherapy alone with concomitant radiochemotherapy in advanced-stage oropharynx carcinoma. J Clin Oncol, 22 : 
69-76, 2004

23) Forastiere A.A., Maor M., Weber R.S., Pajak T., Glisson B., Trotti A., Ridge J., Ensley J., Chao C. : Long-term results of Intergroup RTOG 91-11: a phase III trial to preserve the larynx-induction cisplatin/5-FU and radiation therapy versus concurrent cisplatin and radiation therapy versus radiation therapy. J Clin Oncol, 24 : Suppl : 284s-284s, 2006.

24) Lefebvre J.L., Chevalier D., Luboinski B., Kirkpatrick A., Collette L., Sahmoud T. : Larynx preservation in pyriform sinus cancer : preliminary results of a European Organization for Research and Treatment of Cancer phase III trial. J Natl Cancer Inst, $88:$ 890-899, 1996.

25) Bonner J.A., Harari P.M., Giralt J., Azarnia N., Shin D.M., Cohen R.B., Jones C.U., Sur R., Raben D., Jassem J., Ove R., Kies M.S., Baselga J., Youssoufian H., Amellal N., Rowinsky E.K., Ang K.K. : Radiotherapy plus cetuximab for squamous-cell carcinoma of the head and neck. N Engl J Med, 354 : 567-578, 2006.

26) Posner M.R., Haddad R.I., Wirth L., Norris C.M., Goguen L.A., Mahadevan A., Sullivan C., Tishler R.B. : Induction chemotherapy in locally advanced squamous cell cancer of the head and neck : evolution of the sequential treatment approach. Semin Oncol, 31 : 778-785, 2004.

27) Trotti A., Bellm L.A., Epstein J.B., Frame D., Fuchs H.J., Gwede C.K., Komaroff E., Nalysnyk L., Zilberberg M.D. : Mucositis incidence, severity and associated outcomes in patients with head and neck cancer receiving radiotherapy with or without chemotherapy: a systematic literature review. Radiother Oncol, 66: 253-262, 2003.

28) Chambers M.S., Garden A.S., Kies M.S., Martin J.W.: Radiation-induced xerostomia in patients with head and neck cancer : pathogenesis, impact on quality of life, and management. Head Neck, 26: 796-807, 2004.

29) Nguyen L.N., Ang K.K. : Radiotherapy for cancer of the head and neck : altered fractionation regimens. Lancet Oncol, 3: 693-701, 2002.

30) Bourhis J., Etessami A., Wilbault P., Lusinchi A., Calais G., Lapeyre M., Pignon J.P.: Altered fractionated radiotherapy in the management of head and neck carcinomas: advantages and limitations. Curr Opin Oncol, 16 : 215-219, 2004.

31) Russo G., Haddad R., Posner M., Machtay M. : Radiation treatment breaks and ulcerative mucositis in head and neck cancer. Oncologist, $13: 886-898,2008$.

32) Akimoto T., Mitsuhashi N., Hayakawa K., Sakurai H., Murata O., Ishizeki K., Ishikawa H., Nasu S., Yamakawa M., Niibe H. : Split-course accelerated hyperfractionation radiotherapy for advanced head and neck cancer : Influence of split time and overall treatment time on local control. Jpn J Clin Oncol, 27 : 240-243, 1997.

33) Bernier J., Domenge C., Ozsahin M., Matuszewska K., Lefêbvre J.L., Greiner R.H., Giralt J., Maingon P., Rolland F., Bolla M., Cognetti F., Bourhis J., Kirkpatrick A., van Glabbeke M.: European Organization for Research and Treatment of Cancer Trial 22931. Postoperative irradiation with or without concomitant chemotherapy for locally advanced head and neck cancer. N Engl J Med, 350 : 1945-1952, 2004.

34) Cooper J.S., Pajak T.F., Forastiere A.A., Jacobs J., Campbell B.H., Saxman S.B., Kish J.A., Kim H.E., Cmelak A.J., Rotman M., Machtay M., Ensley J.F., Chao K.S., Schultz C.J., Lee N., Fu K.K. : Radiation Therapy Oncology Group 9501/Intergroup. Postoperative concurrent radiotherapy and chemotherapy for high-risk squamous cell carcinoma of the head and neck. N Engl J Med, 350 : 1937-1944, 2004.

35) Bieri S., Bentzen S.M., Huguenin P., Allal A.S., Cozzi L., Landmann C., Monney M., Bernier J. : Early morbidity after radiotherapy with or without chemotherapy in advanced head and neck cancer. Experience from four nonrandomized studies. Strahlenther Onkol, 179: 390-395, 2003.

36) Harari P.M. : Promising new advances in head and neck radiotherapy. Annals of Oncology, 16 (Suppl 6) : vi13-vi19, 2005.

37) Datta N., Bose A., Keppor H., Gupta S. : Head and neck cancers : results of thermoradiotherapy versus radiotherapy. Int J Hyperthermia, $6:$ 479-486, 1990.

38) Overgaard J., González González D., Hushof M.C., Arcangeli G., Dahl O., Mella O., Bentzen, S.M. : Randomized trial 
of hyperthermia as adjuvant to radiotherapy for recurrent or metastatic malignant melanoma. European Society for Hyperthermic Oncology. Lancet, 3 : 345-540, 1995.

39) Sneed P.K., Stauffer P.R., McDermott M.W., Diederich C.J., Lamborn K.R., Prados M.D., Chang S., Weaver K.A., Spry. L, Malec M.K., Lamb S.A., Voss B., Davis R.L., Wara W.M., Larson D.A., Phillips T.L., Gutin P.H. : Survival benefit of hyperthermia in a prospective randomized trial of brachytherapy boost + /_hyperthermia for glioblastoma multiforme. Int J Radiat Oncol Biol Phys, 40 : 287-295, 1998.

40) Sugimachi K., Kuwano H., Ide H., Toge T., Saku M., Oshiumi Y.: Chemotherapy combined with or without hyperthermia for patients with oesophageal carcinoma : a prospective randomized trial. Int J Hyperthermia, 10 : 485493, 1994.

41) Valdagni R., Amichetti M. : Report of long-term follow up in a randomized trial comparing radiation therapy and radiation therapy plus hyperthermia to metastatic lymph nodes in stage IV head and neck patients. IntJ Radiat Oncol Biol Phys, 28 : 163-169, 1994.

42) van der Zee J., Gonzalez D., van Rhoon G., van Dijk J., van PuttenW., Hart A. : Comparison of radiotherapy alone with radiotherapy plus hyperthermia in locally advanced pelvic tumours : a prospective, randomised, multicentre trial. Dutch Deep Hyperthermia Group. Lancet, 355 : 1119-1125, 2000.

43) Vernon C.C., Hand J.W., Field S.B., Machin D., Whaley J.B., van der Zee J., van Putten W.L., van Rhoon G.C., van Dijk J.D., González González D., Liu F.F., Goodman P., Sherar M. : Radiotherapy with or without hyperthermia in the treatment of superficial localized breast cancer: results from five randomized controlled trials. International Collaborative Hyperthermia Group. Int J Radiat Oncol Biol Phys, 35 : 731-744, 1996.

44) Lazarus C.L., Logemann J.A., Kahrilas P.J., Mittal B.B. : Swallow recovery in an oral cancer patient following surgery, radiotherapy, and hyperthermia. Head Neck, 16: 259-265, 1994.

45) Engin K., Tupchong L., Waterman F.M., Nerlinger R.T., Hoh L.L., McFarlane J.D., Leeper D.B. : Thermoradiotherapy with combined interstitial and external hyperthermia in advanced tumours in the head and neck with depth $>$ or $=3 \mathrm{~cm}$. Int J Hyperthermia, 9: 645-654, 1993.

46) Brizel D.M., Scully S.P., Harrelson J.M., Layfield L.J., Dodge R.K., Charles H.C., Samulski T.V., Prosnitz L.R., Dewhirst M.W. : Radiation therapy and hyperthermia improve the oxygenation of human soft tissue sarcomas. Cancer Res, 56 : 5347-5350, 1996.

47) Jones E.L., Prosnitz L.R., Dewhirst M.W., Marcom P.K., Hardenbergh P.H., Marks L.B., Brizel D.M., Vujaskovic Z. : Thermochemoradiotherapy improves oxygenation in locally advanced breast cancer. Clin Cancer Res, $10:$ 4287-4293, 2004. 